\section{Initiation, evolution, phenotype and outcome of BRCA1 and BRCA2 mutation-associated breast cancer}

\author{
Ke-Da Yu and Zhi-Ming Shao
}

We read with great interest the recent Opinion article (BRCA1 and BRCA2: different roles in a common pathway of genome protection. Nature Rev. Cancer 12, 68-78 $(2012))^{1}$ by Roy et al., in which the authors present the current knowledge of BRCA1 and BRCA2 in genome protection and cancer development. BRCA1 and BRCA2 are known to function in homologous recombination (HR), and they also function in different stages of the DNA damage response. Notably, the functional roles of BRCA1 and BRCA2 are mainly involved in HR, the alteration of which closely relates to DNA damage-associated breast carcinogenesis but which does not explain the formation of specific breast cancer phenotypes in patients with BRCA1 or BRCA2 mutations. BRCA1-mutated cancer tends to be basallike, and BRCA2-mutated cancer tends to be luminal-like, although mechanistically there is no convincing evidence that BRCA1 mutation induces basal progenitor cancer cells or that BRCA2 mutation corresponds to luminal progenitor cancer cells at the early stages of carcinogenesis ${ }^{2}$. An important issue, which was not mentioned in the article by Roy et al., is the question of at what time during tumorigenesis do BRCA1 and BRCA2 mutations begin to individually influence breast cancer subtypes.

The authors proposed that hormonally driven growth during each menstrual cycle produces reactive oxygen species (ROS), which cause measurable oxidative DNA damage that is needed for breast carcinogenesis, and which might explain the breast tissue tropism that occurs in women with BRCA1 or BRCA 2 mutations. We agree with their speculation that long-term and repeated exposure to ROS, as well as to genotoxic or mutagenic oestrogen metabolites, are important risk factors for breast cancer ${ }^{3}$. As hormone-associated ROS and oestrogen metabolites are encountered by all normal breast cells regardless of oestrogen receptor (ER) or HER2 status, and as $\mathrm{HR}$ is not preferentially activated in different subpopulations of cells in the breast, it seems that BRCA1 and BRCA2 mutations do not contribute to the formation of breast cancer subtypes at the very beginning of cancer initiation. In addition, the facts that the loss of the wild-type allele of $B R C A 1$ or $B R C A 2$ is not required for BRCA1 or BRCA2 mutation-associated breast carcinogenesis ${ }^{4}$, and that common breast cancer susceptibility alleles are also associated with BRCA 1 and BRCA2 mutation-associated tumours $^{5}$, consistently suggest that BRCA1 and BRCA2 mutations are not the unique determinants of tumour initiation. In other words, it is the overwhelming levels of hormonally driven ROS and the defective capability of HR, rather than BRCA1 or BRCA2 mutation only, that determine the initiation of carcinogenesis. Instead, the phenotype of BRCA1 and BRCA2 mutation-associated breast cancer, which is probably not determined by levels of ROS and HR capability, might gradually form in the process of cancer evolution rather than at cancer initiation.

Once preneoplastic or cancerous cells form, the ER pathway becomes important in the evolution of ER-positive cancer cells. At this step, BRCA1 and BRCA2 start to show different effects on the evolution of cancer subtypes. Functional BRCA1 is required for ER expression ${ }^{6}$, and BRCA1 also transcriptionally represses the expression of basal-like genes such as cytokeratin 5 (CK5), CK17 and cadherin $3(\mathrm{CDH} 3)^{7}$. This is a potential mechanism to explain the positive association between basal markers and BRCA1-deficient tumours. As BRCA1 is frequently either mutated or methylated in most hereditary and sporadic breast cancer ${ }^{8,9}$ (although the timing of BRCA1 methylation is unclear), the BRCA1 mutation-associated or low expression-associated cancer tends to evolve a basal-like subtype ${ }^{10,11}$. For BRCA2, which can be transcriptionally regulated by $\mathrm{ER}^{12}$, the precise mechanism through which BRCA2-mutated cancer cells finally develop to luminal-like subtype (ER-positive) tumours is unknown.

Theoretically, different phenotypes of breast cancer might lead to altered outcomes. In Table 3 of their article ${ }^{1}$, the authors stated no difference in prognosis between BRCA1- and BRCA2-mutated cancer and sporadic cancer at the same stage. However, studies exhibit inconsistent results (TABLE 1). A meta-analysis showed that BRCA1 mutation decreases short-term and long-term overall survival and short-term progressionfree survival, but BRCA2 mutation does not affect either ${ }^{13}$. The difference in prognosis between BRCA1 and BRCA2 mutationassociated tumours could be due to the difference in clinical phenotype. Another new prospective population-based cohort study showed that the outcomes of BRCA1mutation carriers were similar to those of patients with sporadic breast cancer, whereas the risk of death was higher in BRCA2mutation carriers relative to sporadic cases before adjustment ${ }^{14}$. Interestingly, a pooled analysis showed that BRCA2-mutation carriers with invasive epithelial ovarian cancer have a more favourable survival even when compared with BRCA1-mutation carriers ${ }^{15}$. Because of the inconsistent results in prognosis for BRCA mutation-associated cancers, future data from large prospective cohort studies are warranted.

\begin{tabular}{|c|c|c|c|c|c|}
\hline $\begin{array}{l}\text { Cancer } \\
\text { type }\end{array}$ & Design & $\begin{array}{l}\text { Number of } \\
\text { patients with } \\
\text { BRCA1 mutation, } \\
\text { BRCA2 mutation } \\
\text { or non-carriers }\end{array}$ & $\begin{array}{l}\text { Patients } \\
\text { with BRCA1 } \\
\text { mutation versus } \\
\text { non-carriers } \\
\text { OR }(95 \% \mathrm{Cl})\end{array}$ & $\begin{array}{l}\text { Patients } \\
\text { with BRCA2 } \\
\text { mutation versus } \\
\text { non-carriers } \\
\text { OR }(95 \% \mathrm{Cl})\end{array}$ & Survival \\
\hline $\begin{array}{l}\text { Breast } \\
\text { cancer }\end{array}$ & $\begin{array}{l}\text { Meta- } \\
\text { analysis }^{13}\end{array}$ & $\begin{array}{l}\text { BRCA1 } 501 \\
\text { BRCA2 } 269 \\
\text { Non-carriers 3,154* }\end{array}$ & $1.92(1.45-2.53)$ & $1.30(0.95-1.76)$ & $\begin{array}{l}\text { Short-term } \\
\text { OS (4-5 } \\
\text { years) }\end{array}$ \\
\hline $\begin{array}{l}\text { Breast } \\
\text { cancer }\end{array}$ & $\begin{array}{l}\text { Meta- } \\
\text { analysis }^{13}\end{array}$ & $\begin{array}{l}\text { BRCA1 } 501 \\
\text { BRCA2 } 269 \\
\text { Non-carriers 3,154* }\end{array}$ & $1.33(1.12-1.58)$ & $1.12(0.86-1.45)$ & $\begin{array}{l}\text { Long-term } \\
\text { OS (10-20 } \\
\text { years) }\end{array}$ \\
\hline $\begin{array}{l}\text { Invasive } \\
\text { EOC }\end{array}$ & $\begin{array}{l}\text { Pooled } \\
\text { analysis }^{15}\end{array}$ & $\begin{array}{l}\text { BRCA1 } 909 \\
\text { BRCA2 } 304 \\
\text { Non-carriers 2,666 }\end{array}$ & $0.73(0.64-0.84)$ & $0.49(0.39-0.61)$ & $\begin{array}{l}\text { Adjusted } \\
\text { 5-year OS }\end{array}$ \\
\hline
\end{tabular}

$\mathrm{Cl}$, confidence interval; EOC, epithelial ovarian cancer; OR, odds ratio; OS, overall survival. * Total number of subjects of the meta-analysis (excluding sporadic cases). 
Ke-Da Yu and Zhi-Ming Shao are at the Department of Breast Surgery, Cancer Center and Cancer Institute, Shanghai Medical College, Fudan University, Shanghai 200032, China, and at the Institutes of Biomedical Science, Fudan University, Shanghai 200032, China. Correspondence to Z.-M.S. e-mail: zhimingshao@yahoo.com doi: 10.1038/nrc3181-c1

1. Roy, R., Chun, J. \& Powell, S. N. BRCA1 and BRCA2 different roles in a common pathway of genome protection. Nature Rev. Cancer 12, 68-78 (2012).

2. Molyneux, G. $\&$ Smalley, M. J. The cell of origin of BRCA1 mutation-associated breast cancer: a cautionary tale of gene expression profiling. J. Mammary Gland Biol. Neoplasia 16, 51-55 (2011)

3. Yager, J. D. \& Davidson, N. E. Estrogen carcinogenesis in breast cancer. N. Engl. J. Med. 354, 270-282 (2006).

4. King, T. A. et al. Heterogenic loss of the wild-type BRCA allele in human breast tumorigenesis. Ann. Surg. Oncol. 14, 2510-2518 (2007).

5. Mulligan, A. M. et al. Common breast cancer susceptibility alleles are associated with tumour subtypes in BRCA1 and BRCA2 mutation carriers: results from the Consortium of Investigators of Modifiers of BRCA1/2. Breast Cancer Res. 13, R 110 (2011).

6. Hosey, A. M. et al. Molecular basis for estrogen receptor alpha deficiency in BRCA 1 -linked breast cancer. J. Natl Cancer Inst. 99, 1683-1694 (2007).
7. Gorski, J. J. et al. BRCA1 transcriptionally regulates genes associated with the basal-like phenotype in breas cancer. Breast Cancer Res. Treat 122, 721-731 (2010).

8. Birgisdottir, V. et al. Epigenetic silencing and deletion of the BRCA1 gene in sporadic breast cancer. Breast Cancer Res. 8, R38 (2006)

9. Pang, D. et al. Methylation profiles of the BRCA1 promoter in hereditary and sporadic breast cancer among Han Chinese. Med. Oncol. 11 Nov 2011 (doi:10.1007/s12032-011-0100-0).

10. Foulkes, W. D. et al. Germline BRCA1 mutations and a basal epithelial phenotype in breast cancer. J. Natl Cancer Inst. 95, 1482-1485 (2003).

11. Stefansson, O. A. et al. CpG island hypermethylation of BRCA 1 and loss of $\mathrm{pRb}$ as co-occurring events in basal/triple-negative breast cancer. Epigenetics 6 , 638-649 (2011).

12. Jin, W. et al. Estrogen receptor (ER) $\beta$ or $p 53$ attenuates ER $\alpha$-mediated transcriptional activation on the BRCA2 promoter. J. Biol. Chem. 283, 29671-29680 (2008).

13. Lee, E. H. et al. Effect of BRCA $1 / 2$ mutation on short term and long-term breast cancer survival: a systematic review and meta-analysis. Breast Cancer Res. Treat 122, 11-25 (2010).

14. Goodwin, P. J. et al. Breast cancer prognosis in BRCA1 and BRCA2 mutation carriers: an International Prospective Breast Cancer Family Registry population-based cohort study. J. Clin. Oncol. 30, 19-26 (2012).

15. Bolton, K. L. et al. Association between BRCA1 and BRCA2 mutations and survival in women with invasive epithelial ovarian cancer. JAMA 307, 382-390 (2012).

Competing interests statement

The authors declare no competing financial interests. 